\title{
COMPUTER IMAGE ANALYSIS OF MALARIAL PLASMODIUM VIVAX IN HUMAN RED BLOOD CELLS
}

André von Mühlen, MS - California Polytechnic State University, San Luis Obispo Contact: andrevm@msn.com

\section{Introduction}

This project aims to study computer image analysis of malarial parasites using morphological operators as its main method of approach. Malaria is a life-threatening parasitic disease transmitted through female Anopheles mosquitoes (1). It is found throughout the tropical and subtropical regions of the world (figure 1), and affects over 300 million people annually. As globalization, ease and frequency of travel increase, malaria cases may occur in any country (2). Over one million people die due to malaria every year (3).

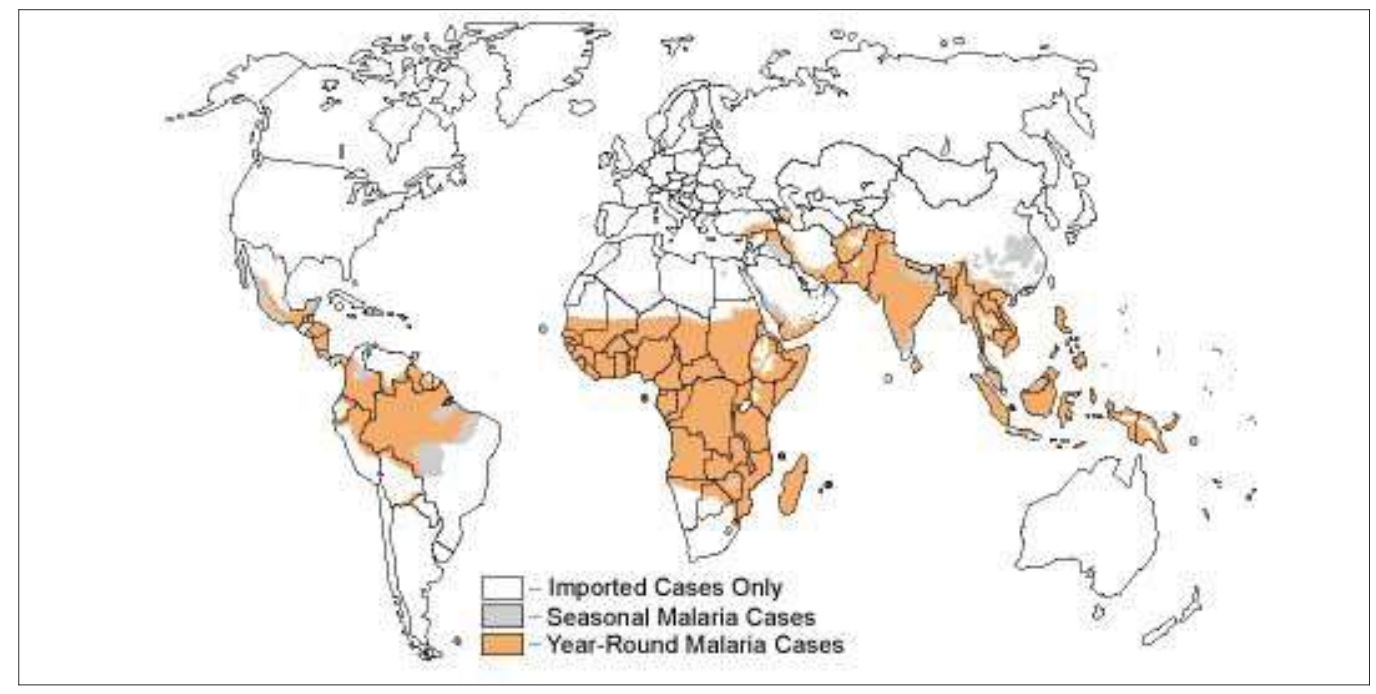

Figure 1. Prevalence of malaria around the world

(Roll Back Malaria. Online. 28 March, 2004)

Malaria is a curable disease and is not an inevitable burden if those suffering from this infection have access to early diagnosis and prompt treatment (3). The "gold standard" for diagnosis involves examination of Giemsa-stained' thick and thin blood smears under a microscope by an expert in examination of blood smears for malaria parasites (4-5). This procedure is neither $100 \%$ sensitive nor $100 \%$ specific, since low-level parasitemia and mixed infections are frequently not detected. One study put the detection limit of microscopy at approximately 50 parasites/ $\mu \mathrm{l}(6)$.

Additional methods exist to diagnose malaria, mainly rapid chromatographic assays (similar to a pregnancy test, a color bar shows up on the testing kit if the parasite is present). The main benefits of rapid tests are that they are quick to perform and easy to interpret, and they require no electrical equipment or specialized laboratory facilities (7). However, many negative issues regarding chromatographic tests are of concern: they are expensive (relative to blood films), do not quantify parasite load, have a delayed return to negative due to persistent antigenemia following successful treatment, most products cannot detect or differentiate between different plasmodia apart from $P$. falciparum, and they are not sufficiently sensitive at low parasitic densities (8).

The development of easy, rapid, and accurate tests for detecting malaria is highly desirable. Using the computer as a diagnostic tool, studies have shown that cancer causing skin lesions are identified reliably by image analysis algorithms, and have the potential to become a useful tool for clinicians (9-11). Counting cells and finding parasites in human blood is often challenging and time consuming, especially if many experiments are involved - for instance, in the research for new drugs. Thus, studies have evaluated a variety of methods for algorithms to evaluate sick cells (12-15).

1 A stain that colors DNA only.

Periódico Tchê Química, Porto Alegre: Grupo Tchê Química v. 1, n.2, Ago. 2004 
Unlike microscopy and rapid chromatographic assays, a software algorithm should be able to find parasites in any number of cells or quantity of blood; and the results should come out within minutes. Nonetheless, there are factors that influence the algorithm design that are not critical issues in the diagnosis methods described earlier: lighting variation between image samples, cell size in images, spacing between cells, and physical properties of parasites and white cells. The method of approach to counting cells is similar to Di Ruberto et al. (2002) (15), using a structural disk-shaped element and morphological operations to outline red cells; however, the method to finding the parasites is unique to a filter that delineates the morphology of the physical elements that make up the parasite inside a red cell.

\section{Methodology}

A set of Giemsa-stained blood films was obtained from Brazilian universities for analysis. Six slides had malaria-infected blood smears, and eleven slides had healthy blood smears, which were used as a reference.

Thirty-two digital photographs - 16 with parasites and 16 without parasites in the image - were taken at the Cal Poly Biology Department, with an Olympus microscope BX60 and digital camera DEI-760D. Magnification was set at 1,000X. All images had 1280x1024 pixels.

The algorithm for this project had to consider a number of factors that affect both the overall cell count, and the parasite count. All cells in the images have a physical border around them; however they may not always be clear in digital images, since a large amount of light passes through their bodies. Furthermore, the cells in the pictures are not flat on the slide, but floating in plasma; hence some cells are actually on their side. Due to their 3-dimensional state, some portions of cells do not look as round as one might expect to see. The lack of uniform physical shape means the size of cells varies from 30-100 pixels in the images.

The amount of magnification also has an effect on the algorithm. Since some cells are deeper in blood plasma than others, and the depth of focus of the microscope is very small at $1000 X(0.69 \mu \mathrm{m})$, some cells are out of focus on the images.

Algorithm Code

The first step in this project involves taking the inverse of all images (i.e. black turns to white, white turns to black). This step is required so that points of interest (i.e. cells) are offset from the background prior to converting the image to binary (figures 2 and 3 ).

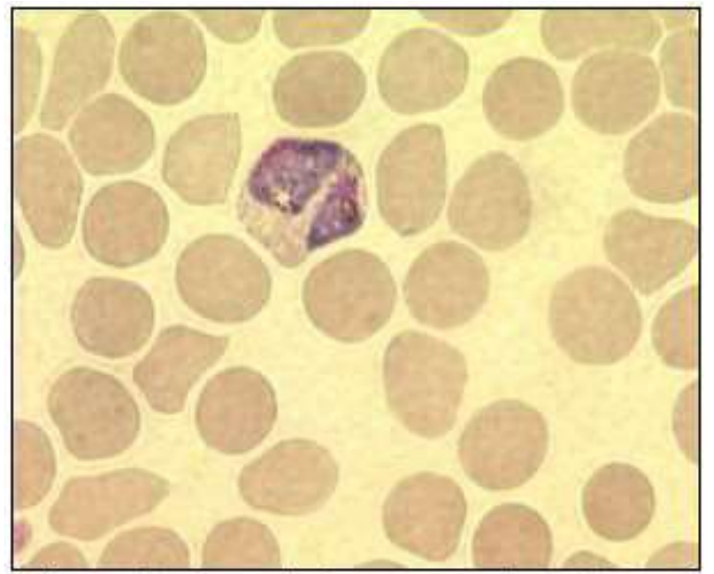

Figure 2. Sample image analyzed by algorithm

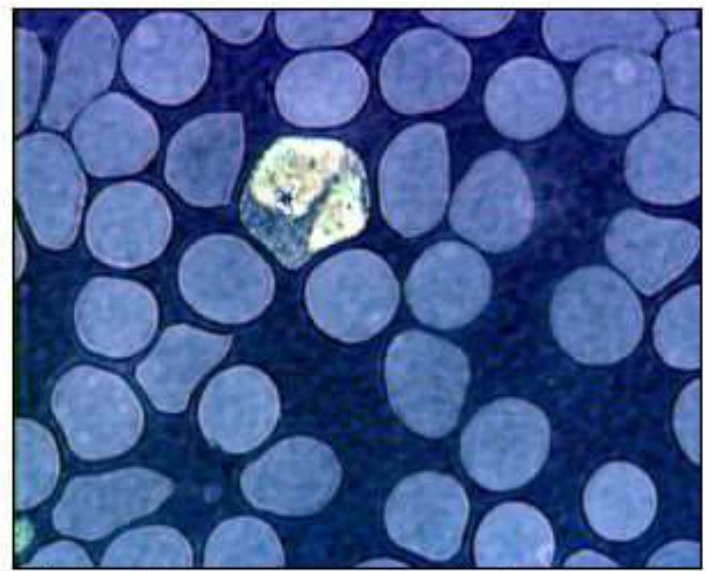

Figure 3 . Inverse of sample image

After reading the inverse images into Matlab, the algorithm can process the cell and parasite count.

The algorithm starts by gathering global threshold level information needed for the binary command. This step highlights bright pixels as white, and dark pixels as black (20). Since the cells are lighter than the background, they receive a value of 1 . The dark background receives a value of 0 . 
One limitation of this command is that a cell exceptionally out of focus may not be bright enough, and therefore not discernible from the background. When the image is turned to binary, the cell is dropped.

The color image is then processed to black and white (figure 4), with a binary command.

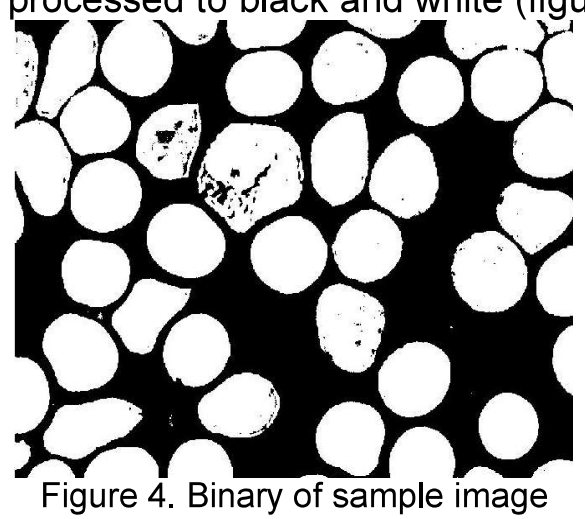

Some cells will show up with holes within them. The cause may be dark spots where not enough light came through, borders that are out of focus, or irregular elements inside, such as a malaria parasite or DNA in a white cell. To prevent these holes from causing cells to be dropped later in the algorithm, a command is used to fill them (figure 5).

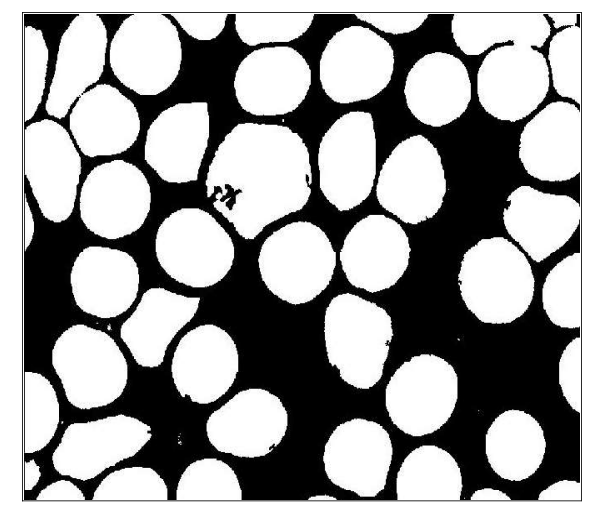

Figure 5. Image after holes were filled

The image at this point still has a few elements that are not relevant, including parts of cells on the periphery of the image (figure 6 , arrow 1 ), and other small elements unknown to the author (arrows 2 and 3). To eliminate these items, a morphological opening is performed, consisting of an erosion and a dilation of the elements on the image (21-22). An essential part of these two operations is the structuring element used to probe the input image (23). A disk function is used to outline the shape of the cells - what the software is supposed to examine, and a radius (number of pixels) is input as the minimum size of the neighborhood of pixels being analyzed. Anything smaller is eliminated.

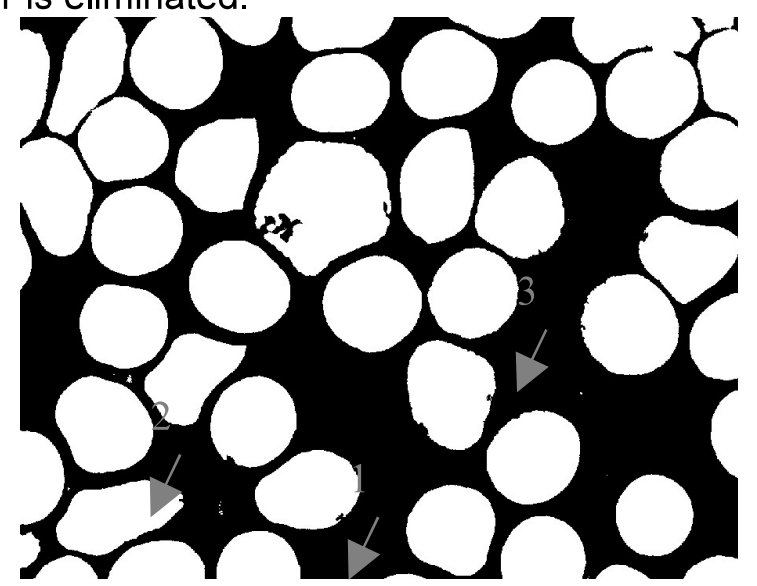

Figure 6. Small elements in sample image 1. Part of a cell, 2-3. Unknown elements 
See figure 7, the new image, clear of any elements smaller than 20 pixels. Notice how the cells have more of a rounded form. Small inlays on the edges are either erased or enlarged.

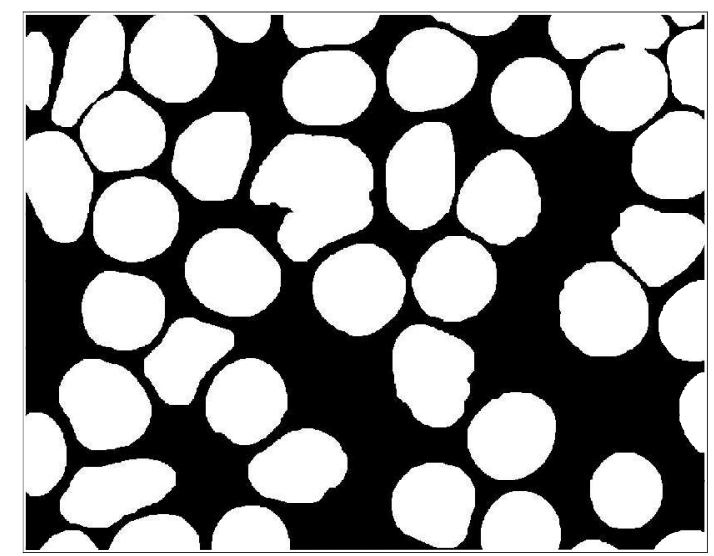

Figure 7. Sample image after morphological operation open

The radius value of 20 pixels provides the optimum count when one wants to use the exact same algorithm code for the entire set of images. However, images taken with a different blood film preparation, magnification, microscope, camera, set of lenses, etc. may have cells of different sizes, which require a different radius value.

Since it is often difficult to differentiate which type of cell is present on the periphery of an image, the algorithm removes them. The largest distance from the border that Matlab allows for analysis is 26 pixels; hence some cells stay in the output (figure 8 ).

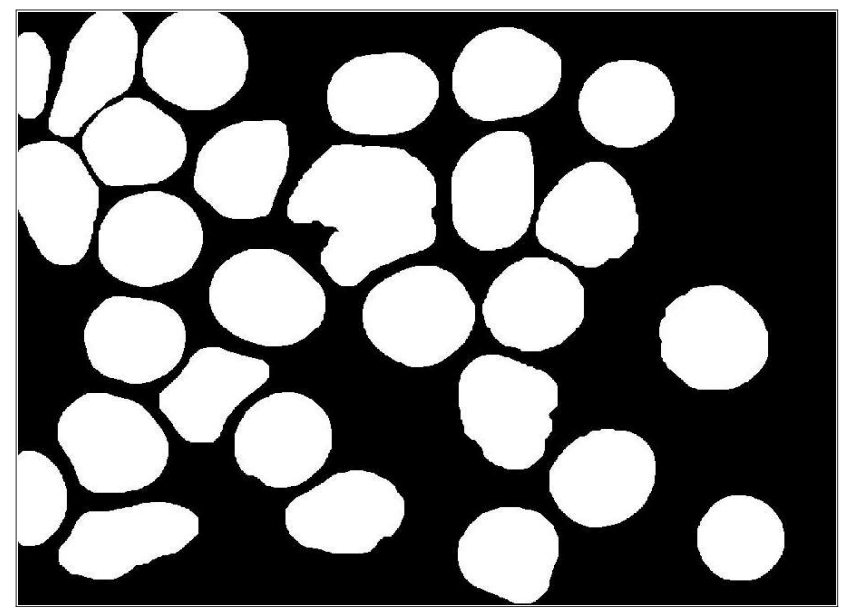

Figure 8. Sample image after clear border command

The Euler number command is now used to count the number of cells. It functions by considering patterns of convexity and concavity in local 2-by-2 pixel neighborhoods (20). The output for the image above is 28 . A manual count of the image indicates there are in fact 28 cells present.

A pre-count of each image was performed manually where only the cells not touching the periphery of the image were considered. The sum for the image above was 28 . Hence, while the algorithm erred in keeping certain cells on the borders (left side of figure 8) and dropping other interconnected cells (see top right of figure 7), it still returned the true count for this image. The implications of this output are detailed in the results and discussion portion of the project.

Two types of cells were found in the images: red and white cells. The computer algorithm has to differentiate between these two types of cells, since both infected red cells and white cells have DNA; which, when Giemsa-stained, have the same color. Healthy red cells do not have DNA. The algorithm takes into account the different physical shapes of each cell by performing a morphological top-hat filter on the inverse image using a structuring element with a 25 -pixel diskshaped radius of the inverse image. 
As the open command removes narrow protrusions or spikes on the contour of cells, and tiny elements altogether, the top-hat filter reveals exactly these residues that the structuring element does not fit (24); hence, all the small elements inside sick red cells come up stronger in the output than healthy red cells (figure 9), or the edges of white cells.

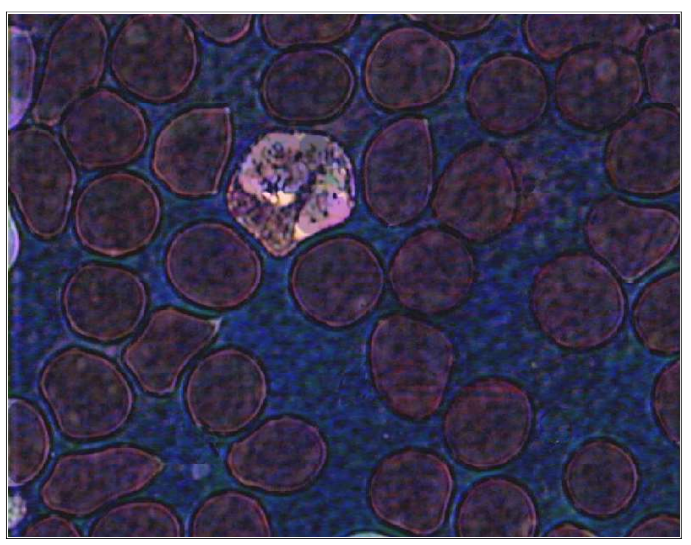

Figure 9. Sample image after top-hat filter

At this point, the algorithm needs the global threshold value discussed earlier to convert to binary. Using the same method discussed earlier, the image is converted to binary (figure 10).

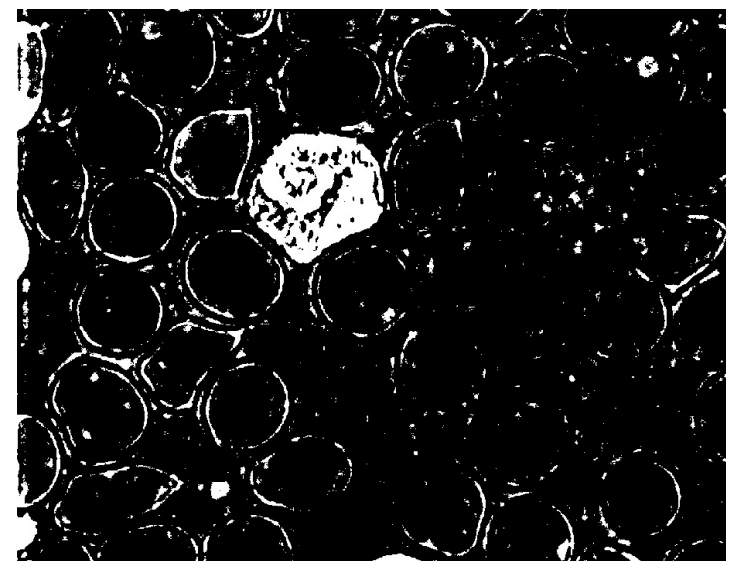

Figure 10. Binary of sample image with parasite

The holes are then filled to prevent the parasite from being dropped along with other smaller elements during the open (figure 11).

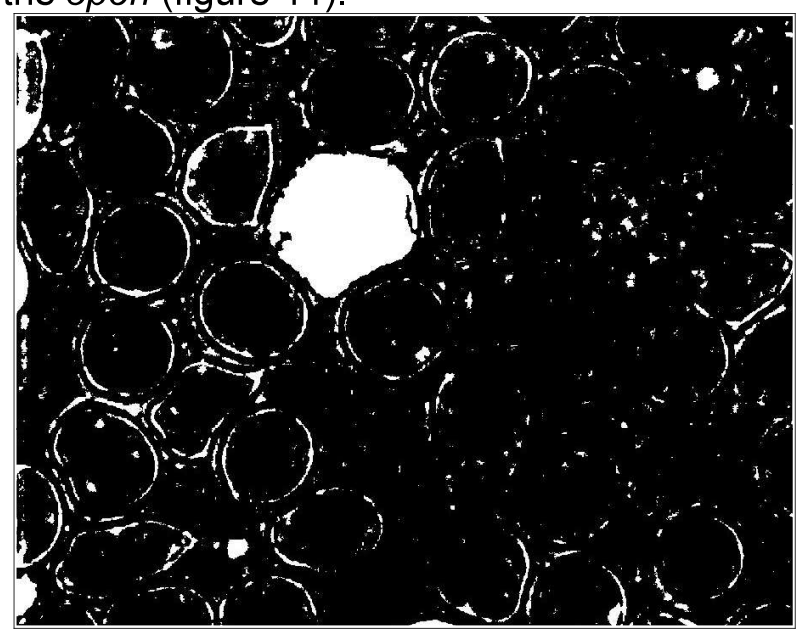

Figure 11. Sample image with parasite and holes filled This command has limitations at this step. Depending on the thickness of the edge of a 
red cell, the fill hole command fills a healthy cell's outline.

Figure 12 illustrates the result of an open with a pixel radius of 26.

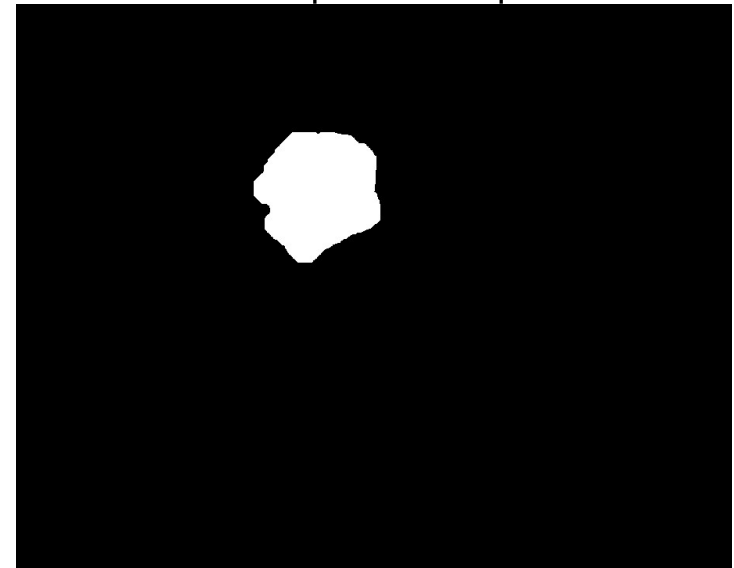

Figure 12. Sample image with parasite after morphological operation open

A smaller radius will not drop enough of the remnant elements on the image; while a larger radius will drop the smaller sick cells found in some images.

The last step in the algorithm is an Euler number command to find the number of parasites. The output is 1 ; which is correct.

See the entire algorithm code in table 1.

\begin{tabular}{l}
\hline \multicolumn{1}{|c|}{ Code } \\
\hline \hline clear \\
I = imread('filename.png'); \\
level = graythresh(I); \\
bw = im2bw(I,level); \\
figure, imshow(bw) \\
bw2 = imfill(bw,'holes') \\
figure, imshow(bw2) \\
background = imopen(bw2,strel('disk',20)); \\
figure, imshow(background) \\
nobrd = imclearborder(background,26) \\
figure, imshow(nobrd) \\
eul = bweuler(nobrd) \\
structure = strel('disk', 25); \\
Itop = imtophat(I, structure); \\
figure, imshow(Itop, []) \\
level = graythresh(Itop); \\
bw = im2bw(Itop,level); \\
figure, imshow(bw) \\
bw2 = imfill(bw,'holes') \\
figure, imshow(bw2) \\
background2 = imopen(bw2,strel('disk',26)); \\
figure, imshow(background2) \\
eul = bweuler(background2)
\end{tabular}

Table 1. Algorithm code 


\section{Results}

Table 2 shows the number of cells in each image per a manual count by the author (where only cells within the image boundaries are considered), whether there is a parasite or not in each image, the algorithm output for the total number of cells (includes white cells, and healthy and sick red cells), the actual number of sick cells, and the algorithm output for the number of sick cells.

\begin{tabular}{|c|c|c|c|c|c|}
\hline $\begin{array}{l}\text { Photo } \\
\text { Number }\end{array}$ & $\begin{array}{c}\text { Sick } \\
\text { (YES/NO) }\end{array}$ & $\begin{array}{c}\text { Actual } \\
\text { Count: } \\
\text { Total } \\
\text { Number of } \\
\text { Cells }\end{array}$ & $\begin{array}{l}\text { Algorithm } \\
\text { Count: } \\
\text { Total } \\
\text { Number of } \\
\text { Cells }\end{array}$ & $\begin{array}{l}\text { Actual } \\
\text { Number of } \\
\text { Sick Cells }\end{array}$ & $\begin{array}{l}\text { Algorithm } \\
\text { Count of } \\
\text { Sick Cells }\end{array}$ \\
\hline 1 & NO & 25 & 24 & 0 & 0 \\
\hline 2 & YES & 25 & 27 & 1 & 1 \\
\hline 3 & YES & 24 & 24 & 1 & 1 \\
\hline 4 & YES & 28 & 28 & 1 & 1 \\
\hline 5 & YES & 24 & 30 & 1 & 1 \\
\hline 6 & NO & 20 & 20 & 0 & 0 \\
\hline 7 & NO & 15 & 15 & 0 & 0 \\
\hline 8 & NO & 25 & 24 & 0 & 0 \\
\hline 9 & YES & 13 & 14 & 1 & 1 \\
\hline 10 & YES & 23 & 25 & 1 & 2 \\
\hline 11 & YES & 30 & 30 & 1 & 1 \\
\hline 12 & YES & 25 & 22 & 2 & 2 \\
\hline 13 & NO & 21 & 17 & 0 & 0 \\
\hline 14 & NO & 20 & 17 & 0 & 0 \\
\hline 15 & YES & 34 & 37 & 2 & 2 \\
\hline 16 & YES & 28 & 29 & 1 & 1 \\
\hline 17 & NO & 16 & 16 & 0 & 0 \\
\hline 18 & NO & 21 & 21 & 0 & 1 \\
\hline 19 & NO & 19 & 19 & 0 & 0 \\
\hline 20 & NO & 15 & 17 & 0 & 2 \\
\hline 21 & YES & 23 & 28 & 0 & 0 \\
\hline 22 & NO & 22 & 20 & 0 & 0 \\
\hline 23 & YES & 18 & 18 & 1 & 1 \\
\hline 24 & YES & 18 & 14 & 2 & 2 \\
\hline 25 & YES & 27 & 28 & 1 & 1 \\
\hline 26 & YES & 25 & 25 & 1 & 2 \\
\hline
\end{tabular}

Table 2. Results of actual count and algorithm output

From the initial 32 images taken, only 26 were analyzed. Six images were dropped because the algorithm could not process them, leading to inconclusive results. There are three groups of reason that influenced this decision: blood film preparation, quality of images, and algorithm design.

Blood film preparation considers lack of spacing between cells, and other elements in the images the author could not identify. The better the spacing, the more accurate the count.

Quality of images considers focus, and too much or too little lighting through cells; hence they blend with the background. A set of images where every cell is in focus provides for better results.

Algorithm design considers limitations by the algorithm that should be worked out in future research.

Table 3 shows the total number of cells in all the images, the algorithm count, the total 
number of sick cells, and the pertaining algorithm count. It also lists the total number of cells missed by the algorithm, healthy and sick. This information is used in the following equations to count the error rates of the algorithm for percentage of cells missed and over counted, and percentage of sick cells missed and over counted.

\begin{tabular}{|c|c|c|c|c|c|}
\hline $\begin{array}{c}\text { Actual } \\
\text { Count: } \\
\text { Total } \\
\text { Number of } \\
\text { Cells }\end{array}$ & $\begin{array}{c}\text { Algorithm } \\
\text { Count: } \\
\text { Total } \\
\text { Number of } \\
\text { Cells }\end{array}$ & $\begin{array}{c}\text { Total } \\
\text { Number of } \\
\text { Cells } \\
\text { Missed }\end{array}$ & $\begin{array}{c}\text { Actual } \\
\text { Number of } \\
\text { Sick Cells }\end{array}$ & $\begin{array}{c}\text { Algorithm } \\
\text { Count of } \\
\text { Sick Cells }\end{array}$ & $\begin{array}{c}\text { Total } \\
\text { Number } \\
\text { of Sick } \\
\text { Cells } \\
\text { Missed }\end{array}$ \\
\hline \hline 584 & 589 & 19 & 17 & 22 & 1 \\
\hline
\end{tabular}

Table 3. Total number of cells and parasites, and pertaining algorithm count total

$$
\text { Percentage of cells missed }=\frac{\text { total number of cells missed }}{\text { total number of cells } 584}=\frac{19}{58}=3 \%
$$

The algorithm missed $3.3 \%$ of the cells due to physical contact between cells. A lack of discernible separation between two cells is counted as one cell by the software. The border drop command also dropped whole cells touching partial cells on the border.

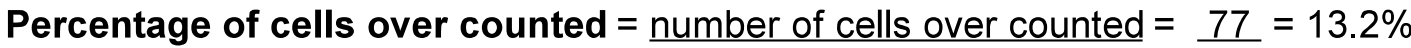 total number of cells 584}

Cells over counted came from the border of the images and small unidentified elements. These were not counted in the manual count, hence the disparity of $13.2 \%$.

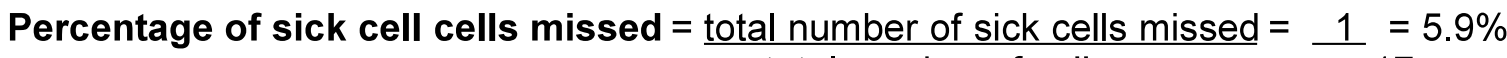 total number of cells -17}

The algorithm missed one parasite an image. The cell had very dispersed elements and its binary cell image did not fill with the fill-hole command, hence it was dropped after the open. Note that another healthy cell was recognized as sick in the same image; thus, the correct count output for this image in table 2.

\section{Percentage of sick cells over counted

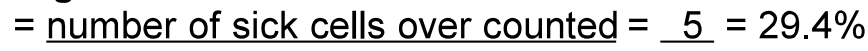 total number of sick cells $\quad 17$}

The algorithm erred in the count of sick cells by almost $30 \%$ over the actual number. The use of blood smears prepared for computer image analysis would decrease this number, due to overall better image quality. The blood smears available for this study were prepared solely for visual microscopy by an expert in malarial analysis. More emphasis on spacing between cells and an overall flat state by cells against the glass on the background would diminish errors.

\section{Discussion and Conclusions}

This study found that the use of computer image analysis of digital images to count the number of cells and detect parasites in blood smears provides a valid diagnosis tool for malaria. Di Ruberto and collaborators were the first researchers to use computer image vision to detect malaria parasites. They used Matlab to count the number of cells by use of gray scale granulometries, and detected parasites by means of an automatic thresholding based on a morphological approach. In similar manner, this project uses morphological operators to count the number of cells; however, it uses a top-hat filter to detect parasites within cells. Both methods seem to provide similar results.

Table 5 outlines the sensitivity, specificity and accuracy of the algorithm - defined by the equations below (25). In table 4, the term positive microscopy represents the number of images that contain the malaria parasite; while negative microscopy represents images with only healthy cells. Algorithm positive represents images that the algorithm found a parasite, whether it was right or not; and algorithm negative represents images the algorithm did not find any parasite. 


\begin{tabular}{|l|c|c|}
\cline { 2 - 3 } \multicolumn{1}{c|}{} & $\begin{array}{c}\text { Positive } \\
\text { Microscopy }\end{array}$ & $\begin{array}{c}\text { Negative } \\
\text { Microscopy }\end{array}$ \\
\hline \hline $\begin{array}{l}\text { Algorithm } \\
\text { Positive }\end{array}$ & $\mathrm{a}$ & $\mathrm{b}$ \\
\hline $\begin{array}{l}\text { Algorithm } \\
\text { Negative }\end{array}$ & $\mathrm{c}$ & $\mathrm{d}$ \\
\hline
\end{tabular}

Table 4. Actual presence of parasite vs. algorithm detection

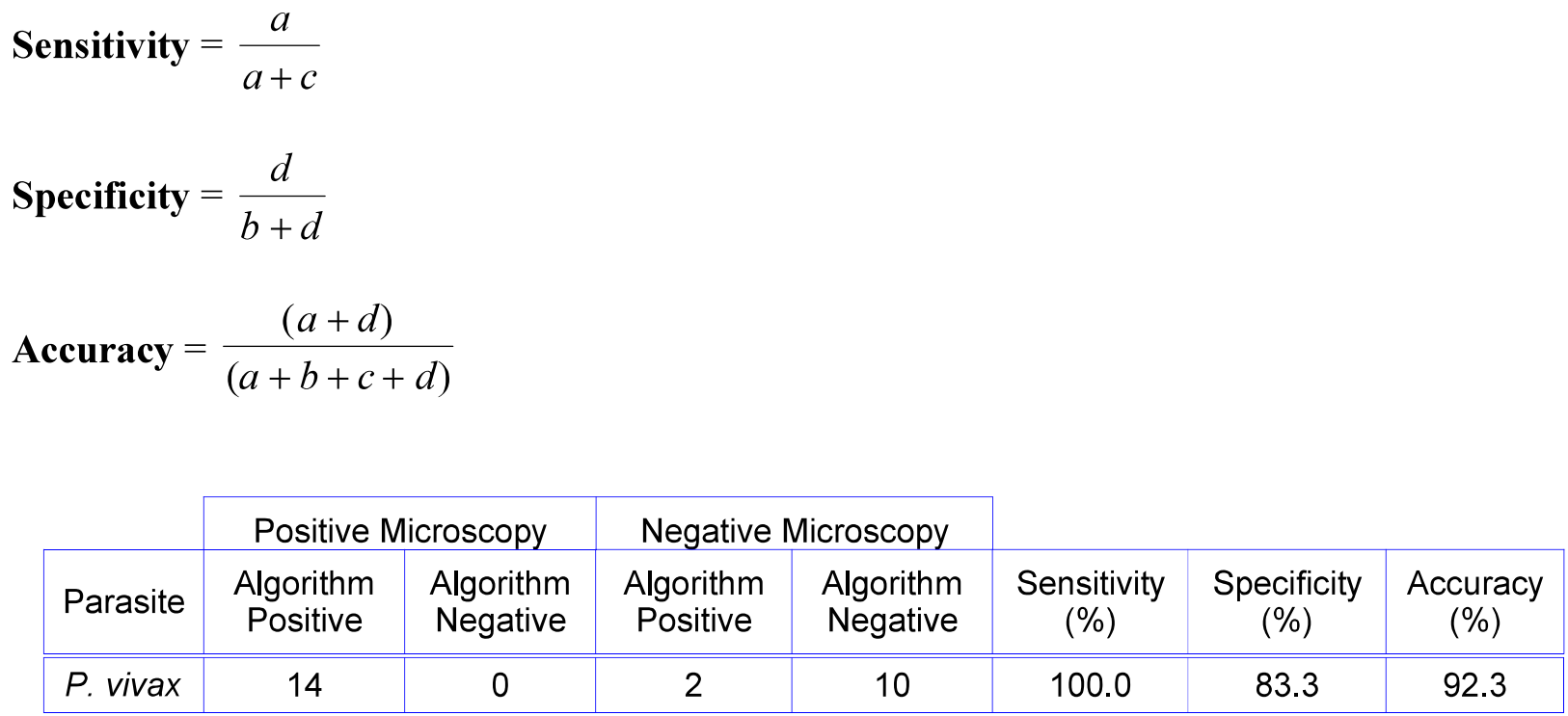

Table 5. Sensitivity, specificity and accuracy of algorithm

The algorithm has high sensitivity, which is desirable since one would like a test of high success rate of detecting positive cases. Inability of the test to correctly identify a true positive might result in missing potential cases of the disease. Conversely, the test is not highly specific at $83.3 \%$, hence there are false positives. Overall, the algorithm had an accuracy of $92.3 \%$, which is considered good under clinical parameters.

The algorithm developed to find and count parasites is a novel alternative to current diagnostic methods. The software is able to find parasites in low quantities and quantify the extent of infection, all in less than five minutes. However, the use of computer image vision requires expensive equipment not available in many countries, mainly those affected by the epidemics. Microscopy continues to be the gold standard for the diagnosis of malaria.

\section{Recommendations for Future Research}

To increase the accuracy of the output, and diminish type I and II errors, the author suggests an algorithm that collects an array of results based on a large number of cycles. The algorithm would adjust one factor per cycle, and compare the output with all the previous runs until the results maintained some consistency; hence it would stop only when it reached a predetermined consensus value (i.e. ten equal cell counts). Factors would include image brightness and contrast, open radius, structuring element radius for the top-hat filter, and perhaps a color overlay for the inverse image. Shades of blue, as seen in the inverse image, might not provide the best basis for collection of thresholding information to binary.

Furthermore, the preparation of the blood smears needs to take into account the purpose of the sample. The better the spacing between cells, the less likely the chance of type I and II errors; where multiple cells were counted as one, and one or more cells were dropped. 


\section{References}

1. What is Malaria? Roll Back Malaria. Online. 26 December 2003. <http://www.rbm.who.int $>$

2. Malaria: Laboratory Diagnosis. Online. 25 December 2003. <http://www.rph.wa.gov.au>

3. World Health Organization. A rapid dipstick antigen capture assay for the diagnosis of falciparum malaria. 74.11 (1996) 47-54

4. Bernard Henry, John. Clinical Diagnosis \& Management, by Laboratory Methods. W.B. Saunders Company. Philadelphia (1991) 1168-1172

5. CJ Palmer, JA Bonilla, DA Bruckner, NS Miller, MA Haseeb, JR Masci, WM Stauffer. Multicenter study to evaluate the OptiMAL test for rapid diagnosis Microbiology. 41.11 (November 2003) 5178-5182

6. J lqbal, N Khalid, PR Hira. Comparison of two commercial assays with expert microscopy for confirmation of symptomatically diagnosed malaria. Journal of Clinical Microbiology. 40.12 (December 2002) $4675-4678$

7. MH Craig, BL Bredenkamp, CH Vuaghan William, EJ Rossouw, VJ Kelly, I Kleinschmidt, A Martineau, and GFJ Henry. Field and laboratory comparative evaluation of ten rapid malaria diagnostic tests. Transactions of the Royal Society of Tropical Medicine and Hygiene. 96 (2002) 258-265

11. RE Coleman, N Maneechai, A Ponlawat, C. Kumptitak, N Rachapaew, RS Miller, and J Sattabongkot. Short report: failure of the OptiMAL rapid malaria test as a tool for the detection of asymptomatic malaria in an area of Thailand endemic for plasmodium falciparum and $p$. vivax. American Society of Tropical Medicine and Hygiene. 67.6 (2002) 563-565

12. H Voigt, and Classen R. Topodermatographic Image Analysis for Melanoma Screening and the Quantitative Assessment of Tumor Dimension Parameters of the Skin. Cancer. 75.4 (15 February, 1995) 981-988

13. JF Aitken, J Pfitzner, D Battistutta, PK O'Rourke, AC Green, NG Martin. Reliability of computer image analysis of pigmented skin lesions of Australian adolescents. Cancer. 78.2 (15 July, 1996) 252-257

14. TW Nattkemper, T Twellmann, H Ritter, W Schubert. Human vs. Machine: Evaluation of Fluorescence Micrographs. Computer in Biology and Medicine. 33 (2003) 31-43

15. H Satelet, O Garraud, M Lorenzato, C Rogier, I Milko-Sartelet, M Huerre, and D Gaillard. Quantitative Computer Image Analysis of Chondroitin Sulfate A Expression in Placentas Infected with Plasmodium Falciparum. The Journal of Histochemistry \& Cytochemistry. 47.6 (1999) 751-756

16. Mohamed Sammouda, Rachid Sammouda, Noboru Niki, Kiyoshi Mukai. Liver cancer detection system based on the analysis of digitized color images of tissue samples obtained using needle biopsy. Information Visualization. 1.2 (Jun 2002) 130

17. R. Barthelson, C Hopkins, and A Mobasseria. Quantitation of bacterial adherence by image analysis. American Journal of Microbiological Methods. 38.1-2 (October 1999) 17-23

18. C Di Ruberto, A Dempster, S Khan, B Jarra. Analysis of Infected Blood Cell Images using Morphological Operators. Image and Vision Computing. 20 (2002) 20133-20146

19. Watershed Algorithm. Online. 10 April, 2004. <http://rsb.info.nih.gov/ij/plugins/watershed.html>

20. G. Adelmann, Holger. Butterworth Equations for Homorphic Filtering of Images. Computers in Biology and Medicine. 28 (1998) 169-181

21. CR Garcia, AR Dluzewski, LH Catalani, R Burting, J Hoyland, and WT Mason. Calcium Homestasic in Intraerythrocytic Malaria Parasites. European Journal of Cell Biology. 71.4 (December 1996) 409-13

22. Intro to PNG Features. Online. 29 March, 2004. <http://www.libpng.org/pub/png/pngintro.html>

23. Matlab 6.5 Help Reference. Software.

24. Morphological Operations. Online. 26 March 2004. <http://rkb.home.cern.ch/rkb/AN16pp/node178.html>

25. What Are Morphological Operations? Online. 26 March 2004. <http://developer.apple.com/documentation/Performance/Conceptual/vImage/Chapter5/>

26. Structuring Elements :: Morphological Operations (Image Processing Toolbox). Online. 19 April, 2004 <http://www.mathworks.com/access/helpdesk/help/toolbox/images/morph5.html\#22581>

27. Residues. Online. 30 April 2004. <http:www.mmorph.com/mmtutor1.0/html/mmtutor/mm045residues.html>

28. Sensitivity and Specificity. Online. 2 May 2004. <http://www.poems.msu.edu/InfoMastery/Diagnosis/SensSpec.htm> 